\title{
NIÓBIO: UM ELEMENTO QUÍMICO ESTRATÉGICO PARA O BRASIL
}

\author{
Carlos G. O. Bruziquesia, Jose Gabriel Balena ${ }^{a}$, Márcio César Pereira ${ }^{b}$, Adilson C. Silva ${ }^{c}$ e Luiz C. A. Oliveira ${ }^{a, *,(\mathbb{D}}$ \\ aDepartamento de Química, Universidade Federal de Minas Gerais, 31270-901 Belo Horizonte - MG, Brasil \\ 'Instituto de Ciência, Engenharia e Tecnologia, Universidade Federal dos Vales do Jequitinhonha e Mucuri, 39803-371 Teófilo \\ Otoni - MG, Brasil
}

'Departamento de Química, Universidade Federal de Ouro Preto, 35400-000 Ouro Preto - MG, Brasil

Recebido em 27/06/2019; aceito em 18/07/2019; publicado na web em 14/11/2019

\begin{abstract}
NIOBIUM: A STRATEGIC CHEMICAL ELEMENT FOR BRAZIL. Niobium, in fact, is an essential element for Brazil. Their applications are so many and so special that they put it as one of the subjects treated by the wikiLeaks site as strategic and that it should be treated in the USA. It is one of the elements most exported by Brazil and is mainly used in the production of special alloys for use in gas pipelines, air turbines, among other applications. It is believed that niobium-based materials can be obtained for applications with higher added value and in equally strategic areas. Research to obtain active and selective drugs, materials to maximize the use of renewable energy, and new nanostructured materials to improve the performance of different components are ongoing and promise a revolution for the next few years.
\end{abstract}

Keywords: niobium compounds; metal alloys; new materials.

\section{INTRODUÇÃO}

O nióbio $(\mathrm{Nb})$ é um elemento de número atômico 41, pertencente à classe dos metais de transição do grupo 5 da tabela periódica. Foi descoberto em 1801 por Charles Hatchett que o batizou de colúmbio, no entanto, o nióbio não foi isolado de sua matriz mineral. ${ }^{1,2} \mathrm{Em}$ 1844, o mineralogista e químico Heinrich Rose isolou e renomeou o então colúmbio de nióbio, em referência a personagem da mitologia grega Níobe, filha do rei Tântalo. ${ }^{3}$ A duplicidade do nome perdurou até 1950, ano em que a IUPAC definiu oficialmente o nome nióbio para o metal de transição. ${ }^{4}$

Três anos após a oficialização do nome nióbio, o geólogo Djalma Guimarães encontrou os primeiros cristais de pandaíta $(\mathrm{Ba}, \mathrm{Sr})_{2}(\mathrm{Nb}, \mathrm{Ti}, \mathrm{Ta})_{2}(\mathrm{O}, \mathrm{OH}, \mathrm{F})_{7}$ no município de Araxá, em Minas Gerais. ${ }^{5,6}$ Tal fato levou à descoberta das jazidas de pirocloro e, consequentemente, a mudança radical nos preços de nióbio no mercado mundial, que antes era extraído em minerais menos comuns como a columbita e tantalita. ${ }^{5} \mathrm{O}$ pirocloro $\left(\mathrm{Na}_{3}, \mathrm{Ca}\right)_{2}(\mathrm{Nb}, \mathrm{Ti})(\mathrm{O}, \mathrm{F})_{7}$ (Figura 1$)$ é um mineral de origem carbonatítica com teor máximo de $71 \%$ de óxido de nióbio $\left(\mathrm{Nb}_{2} \mathrm{O}_{5}\right)$ e suas maiores reservas existentes estão localizadas no Brasil, nos estados de Minas Gerais (Araxá) e Goiás (Catalão e Ouvidor)..$^{5,7}$

Em Araxá, no estado de Minas Gerais, encontra-se a maior jazida lavrável de pirocloro do mundo. São 742 Mt dispostas a céu aberto numa área de 4,5 km de diâmetro. ${ }^{6,7}$ A Companhia Brasileira de Metalurgia e Mineração (CBMM) é a líder em produção de nióbio no mundo, sendo responsável pela extração, beneficiamento do minério, bem como a produção/desenvolvimento de produtos com valor agregado. ${ }^{9}$ Além de produzir ligas ferro-nióbio ( $\mathrm{Fe}-\mathrm{Nb}$ ), nióbio metálico, a empresa detém toda a produção nacional do $\mathrm{Nb}_{2} \mathrm{O}_{5}$, um insumo químico vastamente utilizado em aplicações tecnológicas.

No estado de Goiás as principais jazidas estão nos municípios de Catalão e Ouvidor, com 82,3 Mt de minérios que são explorados pela Niobrás (antiga Anglo American do Brasil, comprada em 2016 pela China Molybdenum CO). ${ }^{7}$ Segundo o último Anuário Mineral Brasileiro, ${ }^{10}$ esses dois estados foram responsáveis por quase $97 \%$

*e-mail: lcao.ufmg@gmail.com

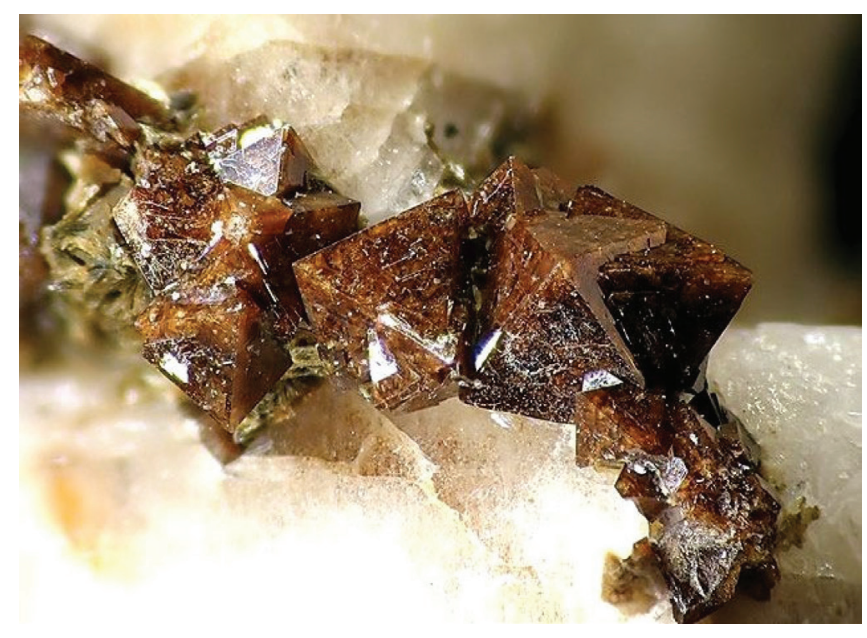

Figura 1. Cristais hexaocataédricos de pirocloro encontrados no monte Malosa, Zomba, República do Maláui. Fotografado por Christian Rewitzer ${ }^{8}$

da produção beneficiária do nióbio em todo o país, sendo que a produção de Minas Gerais, representada pela CBMM, foi quase seis vezes maior que a de Goiás. O Brasil também produz nióbio a partir de columbita e tantalita nos estados do Amazonas e Rondônia, ${ }^{6,7,10}$ mas a produção nem se compara àquela dos estados supracitados. A produção brasileira de concentrado de nióbio anual, assim como seus principais produtos, é mostrada na Figura 2.

O preço FOB ("free on board", refere-se ao preço da mercadoria no local de fabricação ou armazenamento) médio por tonelada de $\mathrm{Nb}_{2} \mathrm{O}_{5}$ e de liga Fe-Nb nos últimos anos foi de US\$37.108 e 31.202, respectivamente. ${ }^{7}$ Praticamente toda a produção do nióbio é voltada para o setor siderúrgico. ${ }^{11}$ No relatório anual de atividades do período de julho de 2017 a junho de 2018 reportado pelo Instituto Brasileiro de Mineração, as ligas Fe-Nb, em termos US\$ FOB, representaram o quarto lugar dos bens minerais mais exportados do país (6\%), ficando atrás apenas do minério de ferro (62\%), ouro (13\%) e cobre (9\%). ${ }^{12}$ Em 2016, os principais importadores das ligas $\mathrm{Fe}-\mathrm{Nb}$ foram os Países Baixos seguido de China, Cingapura e Estados Unidos. 


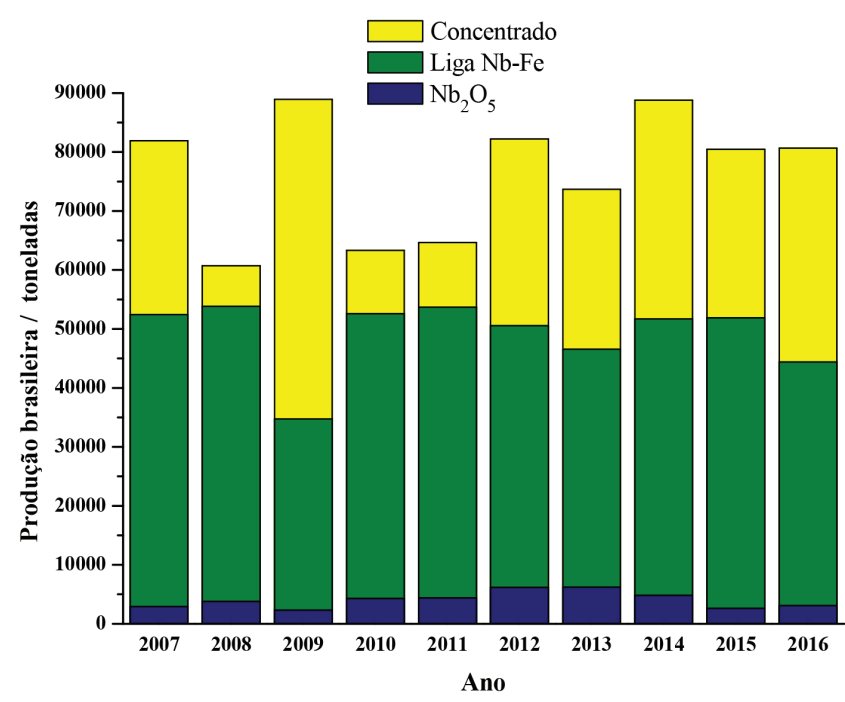

Figura 2. Produção brasileira anual de concentrado de minério (em termos de $\mathrm{Nb}_{2} \mathrm{O}_{5}$ ), ligas $\mathrm{Nb}$-Fe e $\mathrm{Nb}_{2} \mathrm{O}_{5}$ comercial. Os dados foram obtidos dos dez mais recentes sumários minerais fornecidos pela Agência Nacional de Mineração ${ }^{10}$

\section{Uso em ligas}

Mais de $80 \%$ do nióbio produzido é usado em ligas que vão desde aços estruturais até superligas projetadas para suportar altas temperaturas em ambientes extremamente corrosivos. ${ }^{5,11,13}$ Ligas supercondutoras contendo nióbio estão presentes nos magnetos do Grande Colisor de Hádrons, ${ }^{14}$ acelerador de partículas onde foi descoberto o bóson de Higgs, a famosa partícula de Deus (LHC), na fronteira entre França e Suíça. Desde a primeira crise do petróleo (1973), a indústria automobilística tem usado aços formados por microligas de $\mathrm{Nb}$, pois além de sua alta resistência mecânica que garante a segurança do motorista, seu emprego demanda menor quantidade de aço na estrutura do automóvel, tornando-o mais leve e consequentemente reduzindo o consumo de combustível. ${ }^{5,6}$

A resistência do aço depende do teor de carbono em sua composição. No entanto, um aumento gradativo de carbono afeta negativamente as propriedades elementares do processamento desse material, como a maleabilidade, soldabilidade e tenacidade. Uma estratégia para aumentar a resistência das ligas consiste em adicionar elementos que possuem afinidade com o carbono. ${ }^{5}$ Neste contexto, o nióbio possui a capacidade de formação de microligas por apresentar uma boa afinidade com o carbono. A proporção de $\mathrm{Nb}$ nas ligas varia com o tipo de aplicação. Aços microligados comumente consumidos na indústria automobilística têm em sua composição cerca de 0,03 a $0,04 \%$ de nióbio, ${ }^{5,6}$ enquanto ligas especiais usadas em motores a jato, como a Inconel 718, os teores de nióbio chegam a 5,5\%. Ou seja, uma tonelada da liga 718 possui $50 \mathrm{~kg}$ de $\mathrm{Nb}$ puro. ${ }^{15}$

\section{Uso em vidros}

Quando $\mathrm{Nb}_{2} \mathrm{O}_{5}$ é adicionado a vidros especiais para a fabricação de lentes, em materiais bioativos, ou mesmo em capacitores cerâmicos, confere propriedades como alto índice de refração, alta constante dielétrica e aumento da transmitância. ${ }^{5,11}$ Vidros fosfato são estudados em transmissão de dados via fibra óptica, em condutores iônicos, semicondutores, materiais bioativos na substituição de tecidos ósseos e na odontologia. ${ }^{16,17}$ Dentre as vantagens dessa classe de vidros estão (i) a grande variedade de propriedades químicas e físicas; (ii) obtenção de vidros cerâmicos a baixas temperaturas de sinterização e (iii) capacidade de formação de estruturas variadas. ${ }^{18}$ Vidros fosfato podem ainda incluir dopantes capazes de induzir uma função biológica específica melhorando sua biocompatibilidade. ${ }^{19}$ Suas propriedades são governadas pela polarizabilidade da ligação, fortemente dependentes de estruturas microscópicas e da formação de rede. Íons como $\mathrm{Ti}^{4+}, \mathrm{Nb}^{5+}$ e $\mathrm{W}^{6+}$ influenciam positivamente no aumento do índice de refração. ${ }^{20}$ Nióbio ocupa um papel de destaque no melhoramento das propriedades dos vidros fosfatos. Cátions de $\mathrm{Nb}^{5+}$ vêm sendo estudados na fosfatase alcalina, cumprindo uma função importante na formação de novos tecidos ósseos. ${ }^{21}$ Grupos de $\mathrm{Nb}-\mathrm{OH}$ contidos na superfície da nióbia $\left(\mathrm{Nb}_{2} \mathrm{O}_{5}\right)$ agem como centros de nucleação da apatita, exercendo função similar aos grupos silanos $(\mathrm{Si}-\mathrm{OH})$ nas composições de vidros bioativos. ${ }^{22}$ A nióbia aumenta a estabilidade química e mecânica de vidros de fosfato e de cerâmicas vítreas, proporciona aumento na dureza, densidade e módulo elástico. ${ }^{23}$ Vidros altamente homogêneos de composição $\mathrm{Li}_{2} \mathrm{O}-\mathrm{Nb}_{2} \mathrm{O}_{5}-\mathrm{CaO}-$ $\mathrm{P}_{2} \mathrm{O}_{5}$ foram obtidos por fusão a $1350{ }^{\circ} \mathrm{C}$ durante $1 \mathrm{~h}$ em atmosfera de ar usando cadinhos de platina. A mistura fundente é então vertida em pratos de carbono e recozidas a $550{ }^{\circ} \mathrm{C}$ para completar a formação do vidro. Medidas espectroscópicas mostram que a estrutura vítrea consiste em sítios octaédricos de $\mathrm{Nb}^{5+}$ ligados a unidades de piro/ ortofosfato por meio de ligações $\mathrm{Nb}-\mathrm{O}-\mathrm{P}$, conferindo alta polarizabilidade aos sistemas vítreos. ${ }^{24}$ Novas composições de vidro partindo de $\mathrm{KPO}_{3}-\mathrm{Nb}_{2} \mathrm{O}_{5}$ têm sido investigadas usando diversas composições molares (entre $95 \% \mathrm{KPO}_{3}$ e $50 \% \mathrm{KPO}_{3}-50 \% \mathrm{Nb}_{2} \mathrm{O}_{5}$ ). Os autores propuseram um modelo estrutural, em que poliedros de $\mathrm{NbO}_{x}$ estão inseridos em cadeias de fosfato de unidades $\mathrm{PO}_{4}$. Como conclusão, verificaram que uma razão molar de $20 \%$ de $\mathrm{Nb}_{2} \mathrm{O}_{5}$ é mais estável frente o processo de desvitrificação. Teores elevados de $\mathrm{Nb}$ resultam em baixas estabilidades térmicas. ${ }^{25}$

O grupo de Stunda-Zujeva ${ }^{26}$ estudou a capacidade de formação e fases cristalinas do vidro $\mathrm{xP}_{2} \mathrm{O}_{5}-\mathrm{yNb}_{2} \mathrm{O}_{5}-\mathrm{zCaO}-8 \mathrm{Na}_{2} \mathrm{O}$ com o objetivo de compreender melhor a relação entre vidros fosfato e óxidos de elementos de transição. ${ }^{26}$ Eles verificaram que reações em fase sólida entre $\mathrm{P}_{2} \mathrm{O}_{5}$ e $\mathrm{Nb}_{2} \mathrm{O}_{5}$ podem causar alteração no número de oxidação do $\mathrm{Nb}$ que tem um papel fundamental na formação do vidro. Cátion $\mathrm{Nb}^{5+}$ atua como um intermediário ou formador condicional de vidro (vidro fica amarelo), enquanto $\mathrm{Nb}^{4+}$ atua como um modificador de vidro (vidro fica azul). Recentemente, novos materiais aplicados à regeneração de tecidos ósseos vêm sendo desenvolvidos. Comercialmente está disponível um vidro bioativo, o Bioglass ${ }^{\circledR}$, cuja composição conhecida é $45 \mathrm{~S} 5$ correspondente a $45(\% \mathrm{~m} / \mathrm{m})$ de $\mathrm{SiO}_{2}, 24,5(\% \mathrm{~m} / \mathrm{m})$ de $\mathrm{CaO}, 24,5(\% \mathrm{~m} / \mathrm{m})$ de $\mathrm{Na}_{2} \mathrm{O}$ e $6(\% \mathrm{~m} / \mathrm{m})$ de $\mathrm{P}_{2} \mathrm{O}_{5}$. O Bioglass $®$ vem se destacando em aplicações na área de odontologia e aparelhos ortopédicos. ${ }^{27}$ Todavia, a principal limitação desse biovidro comercial é o seu longo período de degradabilidade, levando de 1 a 2 anos para desaparecer completamente do corpo humano. ${ }^{28}$ Com base nisso, vidros de fosfato vêm sendo estudados como substituintes de vidros de silicato para aplicações biomédicas. Por exemplo, a taxa de degradação de $\mathrm{CaO}-\mathrm{Na}_{2} \mathrm{O}-\mathrm{P}_{2} \mathrm{O}_{5}$ pode variar de horas até semanas, dependendo da composição do vidro. Bertran e colaboradores ${ }^{29}$ estudaram sistema vítreos biocompatíveis usando $\mathrm{SiO}_{2}-\mathrm{Na}_{2} \mathrm{O}-\mathrm{CaO}-\mathrm{P}_{2} \mathrm{O}_{5}-\mathrm{Nb}_{2} \mathrm{O}_{5}$. Partículas de 45S5 Bioglass ${ }^{\circledR}$ em suspensão foram preparadas pela substituição de $\mathrm{P}_{2} \mathrm{O}_{5}$ por até $1,3 \mathrm{~mol} \%$ de $\mathrm{Nb}_{2} \mathrm{O}_{5}$ ou de $\mathrm{SiO}_{2}$ por $1,0 \mathrm{~mol} \%$ de $\mathrm{Nb}_{2} \mathrm{O}_{5}$. O estudo foi dividido em duas séries: (i) substituição de $\mathrm{P}_{2} \mathrm{O}_{5}$ por $\mathrm{Nb}_{2} \mathrm{O}_{5}$ e (ii) substituição de $\mathrm{SiO}_{2}$ por $\mathrm{Nb}_{2} \mathrm{O}_{5}$. Medidas de espectroscopia Raman e ressonância magnética nuclear no estado sólido $\left({ }^{29} \mathrm{Si} \mathrm{MAS}\right.$ - magic angle spinning) mostraram a ligação cruzada entre $\mathrm{Nb}^{5+}$ e vários sítios de $\mathrm{O}$ formando poliedros ( $\mathrm{Nb}$ coordena com até 5 poliedros de $\mathrm{SiO}_{2}$ ) de fórmula geral [ $\left.\mathrm{Nb}(\mathrm{OM})_{6-\mathrm{y}}(\mathrm{OSi})_{\mathrm{y}}\right]$, onde $1 \leq \mathrm{y} \leq 5$ e $\mathrm{M}=\mathrm{Na}, \mathrm{Ca}$, ou P (Figura 3). A adição de $\mathrm{Nb}_{2} \mathrm{O}_{5}$ aumenta significativamente a dureza e a estabilidade do material vítreo.

Vidros cerâmicos de $\mathrm{PbO}-\mathrm{SrO}-\mathrm{Na}_{2} \mathrm{O}-\mathrm{Nb}_{2} \mathrm{O}_{5}-\mathrm{SiO}_{2}$ (PSNNS) foram preparados por deposição física a laser em substratos de 

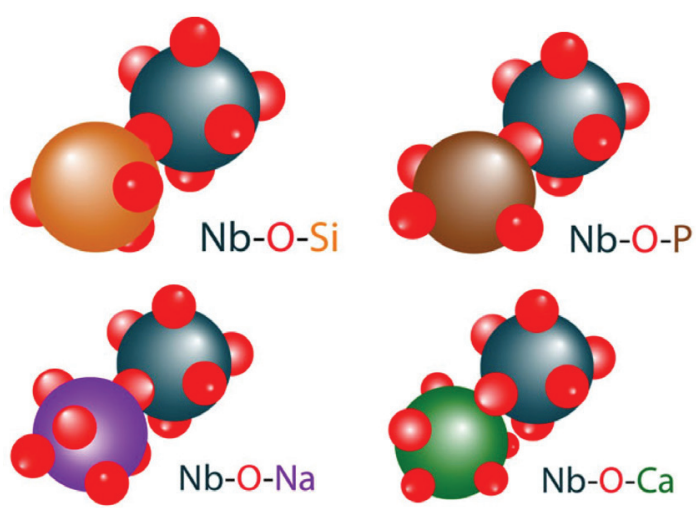

Figura 3. Algumas possibilidades da ligação de $\mathrm{Nb}$ em diferentes séries: $\mathrm{Nb}-\mathrm{O}-\mathrm{Si} ; \mathrm{Nb}-\mathrm{O}-\mathrm{P} ; \mathrm{Nb}-\mathrm{O}-\mathrm{Na} ; \mathrm{Nb}-\mathrm{O}$-Ca. A fórmula geral pode ser escrita como $\left[\mathrm{Nb}(\mathrm{OM})_{\sigma^{-}}(\mathrm{OSi})_{y}\right]$, como $1 \leq y \leq 5$ e $M=N a$, Ca ou P. Adaptado da referência 22

sílica dopados. A influência da temperatura de recozimento dos vidros cerâmicos sobre as microestruturas, propriedades dielétricas e densidade de armazenamento de energia foram estudadas. A fase de $\mathrm{Pb}_{2} \mathrm{Nb}_{2} \mathrm{O}_{7}$ é formada a $800{ }^{\circ} \mathrm{C}$, enquanto a formação de $\mathrm{NaNbO}_{3} \mathrm{e}$ $\mathrm{PbNb}_{2} \mathrm{O}_{6}$ ocorre a $900{ }^{\circ} \mathrm{C}$. O grupo de Tan e colaboradores ${ }^{29}$ observou que as propriedades dielétricas são diretamente influenciadas pelas fases formadas durante o tratamento térmico. Os filmes de PSNNS tratados a $800{ }^{\circ} \mathrm{C}$ apresentaram a maior constante dielétrica de 171 em $10 \mathrm{kHz}$ e densidade de armazenamento de energia de $36,9 \mathrm{~J} \mathrm{~cm}^{-}$ ${ }^{3}$. Estudos recentes mostram a dopagem de $\mathrm{Ag}_{2} \mathrm{O}$ (1\%) em matrizes vítreas de $\mathrm{Li}_{2} \mathrm{O}-\mathrm{Nb}_{2} \mathrm{O}_{5}-\mathrm{P}_{2} \mathrm{O}_{5}$ podem melhorar suas propriedades dielétricas. ${ }^{30}$ Estudos espectrais mostram aglomerados de partículas de prata metálica e íons $\mathrm{Ag}^{+}$nos vidros fabricados. Os vidros dopados com maior teor de $\mathrm{Ag}_{2} \mathrm{O}$ mostraram os maiores valores de constante dielétrica, especialmente em baixas frequências e altas temperaturas.

\section{Uso em baterias}

A demanda por eletricidade per capita e em todos os setores produtivos vêm crescendo nos últimos anos. A energia gerada mundialmente é principalmente oriunda de fontes de energia não-renovável como combustíveis fósseis que causam sérios problemas ambientais devido a liberação de gases poluentes como $\mathrm{CO}_{2}$ que é o principal responsável pelo efeito estufa. Além disso, o esgotamento da reserva mundial de petróleo e a constante variação em seu preço por fatores geopolíticos, vêm despertando interesse coletivo por novas formas de geração de energia de maneira sustentável e economicamente viável. ${ }^{31}$ Dessa forma, o armazenamento de energia ocupa um papel de destaque tanto na geração como no consumo consciente da energia elétrica. Baterias de íon-Li atualmente vêm recebendo atenção devido a possibilidade de aplicação em carros elétricos. Óxidos de nióbio $\left(\mathrm{Nb}_{2} \mathrm{O}_{5}\right)$ mesoporosos com estreita faixa de distribuição de diâmetro de poros, têm sido usados como materiais anódicos para reações de intercalação, amplamente utilizados nas baterias de íons-lítio, proporcionando alta capacidade volumétrica. ${ }^{32}$ Supercapacitores híbridos ocupam uma interface entre os eletrodos de baterias de alta capacidade energética e eletrodos de capacitores de alta potência no âmbito da armazenagem de energia em dispositivos eletroquímicos. ${ }^{33}$ Devido à sua razoável performance cíclica e capacidade moderada, recentemente a nióbia vem sendo estudada em supercapacitores híbridos ainda que apresentando baixa condutividade eletrônica e transporte de íons. ${ }^{34}$ Uma alternativa para contornar essa importante limitação se baseia na incorporação de carbono, ${ }^{35}$ em que nanocompósitos de $\mathrm{Nb}_{2} \mathrm{O}_{5}$ /carbono permitem alta estabilidade cíclica. ${ }^{34}$ Supercapacitores híbridos são preparados partindo de microesferas de $\mathrm{Nb}_{2} \mathrm{O}_{5}$ sintetizadas a partir de matrizes de carbono altamente poroso.
Essas esferas de $\mathrm{Nb}_{2} \mathrm{O}_{5}$ possuem pequeno tamanho de cristalito e alto volume de mesoporos, apresentando boa ciclabilidade e performance. A capacidade de descarga de corrente é de $124 \mathrm{mAh} \mathrm{g}^{-1}$ em 5000 ciclos, e a capacidade de retenção para o segundo ciclo é de $76 \%$. A capacidade de descarga diminuiu aproximadamente $26 \%$ de 171 $\mathrm{mAh} \mathrm{g}^{-1}$ para $127 \mathrm{mAh} \mathrm{g}^{-1}$ quando a densidade de corrente aumenta de $0,5 \mathrm{~A} \mathrm{~g}^{-1}$ para $10 \mathrm{~A} \mathrm{~g}^{-1}$.

Capacitores híbridos de íon-Na combinam o mérito das baterias e supercapacitores. Embora esse dispositivo possua baixo custo relativo, há uma limitação quanto a difusão de $\mathrm{Na}^{+}$no anodo. Para melhorar a difusão de íons $\mathrm{Na}^{+}$no anodo, membranas mesoporosas tem sido preparadas pela deposição de $\mathrm{Nb}_{2} \mathrm{O}_{5}$ ortorrômbico em nanofibra de carbono em $\mathrm{SiO}_{2}$ Essas membranas mesoporosas de $\mathrm{Nb}_{2} \mathrm{O}_{5} / \mathrm{CNF}$ são mecanicamente flexíveis sem a necessidade de adição de aditivos, fixadores ou coletores de correntes. Os mesoporos formados in situ aumentam a capacidade específica e a ciclabilidade da bateria devido à melhora na cinética de difusão de íons $\mathrm{Na}^{+}$no anodo. ${ }^{35}$ Nanopartículas de $\mathrm{Nb}_{2} \mathrm{O}_{5}$ se apresentam como materiais promissores para o anodo de baterias íon- $\mathrm{Li}^{+}$quando preparadas pelo método solvotérmico em meio orgânico ${ }^{33}$ ou métodos hidrotérmicos. ${ }^{36}$ Nanofolhas com diâmetro de $1.4 \mu \mathrm{m}$ e espessura na faixa de 3-4 nm exibiram capacidades de descarga de $247 \mathrm{mAh} \mathrm{g}^{-1}$ a uma densidade de corrente de $20 \mathrm{~mA} \mathrm{~g}{ }^{-1} \cdot{ }^{36} \mathrm{~A}$ nióbia pode ainda ser empregada na fabricação de materiais catódicos. A calcinação de misturas de LiOH. $\mathrm{H}_{2} \mathrm{O}, \mathrm{Nb}_{2} \mathrm{O}_{5}$ e $\mathrm{Ni}_{0,7} \mathrm{Mn}_{0,3}(\mathrm{OH})_{2}$ resulta em um material com potencial aplicação como catodo em baterias de íon-Li. A substituição isomórfica do $\mathrm{Nb}$ na rede de $\mathrm{LiNi}_{0,7} \mathrm{Mn}_{0,3} \mathrm{O}_{2}$ causou uma diminuição da resistência elétrica e aumentou a ciclabilidade do eletrodo. ${ }^{37}$

Estudos objetivando o preparo de materiais catódicos e anódicos contendo óxidos de nióbio permitirão a comercialização de supercapacitores híbridos mais econômicos e eletricamente mais estáveis para aplicação em armazenamento de energia. Sendo assim, grandes esforços nessa área serão necessários como a diminuição do tempo de recarga de uma bateria, que ainda se mantém relativamente alto. A problemática da demanda por combustíveis fósseis ainda há de perdurar por um longo tempo. Uma vez que uma bateria armazena energia elétrica, uma produção energética dessa natureza é um fator crítico, caso se queira cumprir a agenda de uma produção e consumo limpo e sustentável.

\section{Uso em catálise}

Óxidos de nióbio chamam a atenção na área da catálise heterogênea graças à sua inerente estabilidade química, acidez característica e versatilidade. ${ }^{38-40}$ Numerosas são as patentes e os trabalhos publicados na literatura empregando esses sólidos inorgânicos como fase ativa em reações catalíticas, sejam elas com o intuito de produzir seletivamente moléculas de interesse comercial, através de oxidações parciais do substrato, ${ }^{39,41}$ ou até mesmo visando a completa mineralização (oxidação total) de poluentes orgânicos, responsáveis por efeitos deletérios à saúde humana..$^{42}$ A Figura 4 apresenta a produção científica e patentes geradas ao longo dos últimos doze anos sobre a aplicação de óxidos de nióbio (modificados ou não) em reações catalíticas.

As vantagens dos óxidos de nióbio não se limitam ao uso exclusivo como fase ativa, quando pequenas porções de óxidos de nióbio são incorporadas à matriz de outros catalisadores, há um ganho na atividade e na seletividade das reações, além de aumentar a vida útil do catalisador. ${ }^{44}$ Como suporte, as espécies de $\mathrm{Nb}_{2} \mathrm{O}_{5}$ interagem muito bem com óxidos e metais de transição, produzindo catalisadores com propriedades únicas. ${ }^{39,40,44}$ Além disso, substituições isomórficas têm sido feitas em peneiras moleculares com o objetivo de aumentar disponibilidade os sítios ácidos de Lewis e Brönsted desses materiais. ${ }^{39} \mathrm{~A}$ 


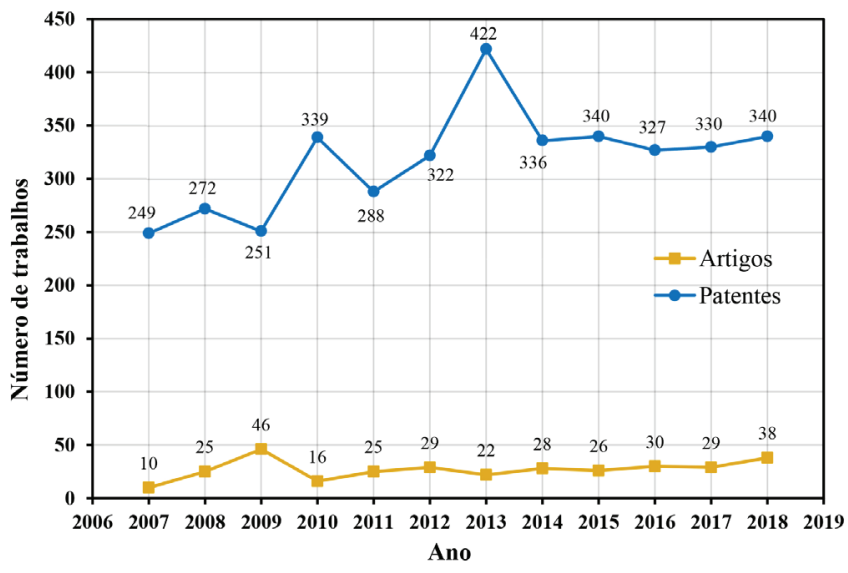

Figura 4. Patentes e artigos científicos gerados nos últimos doze anos sobre aplicações catalíticas de óxidos de nióbio. Os números foram obtidos do banco de dados SciVerse Scopus, pesquisando por "niobium oxide catalysis" ${ }^{43}$

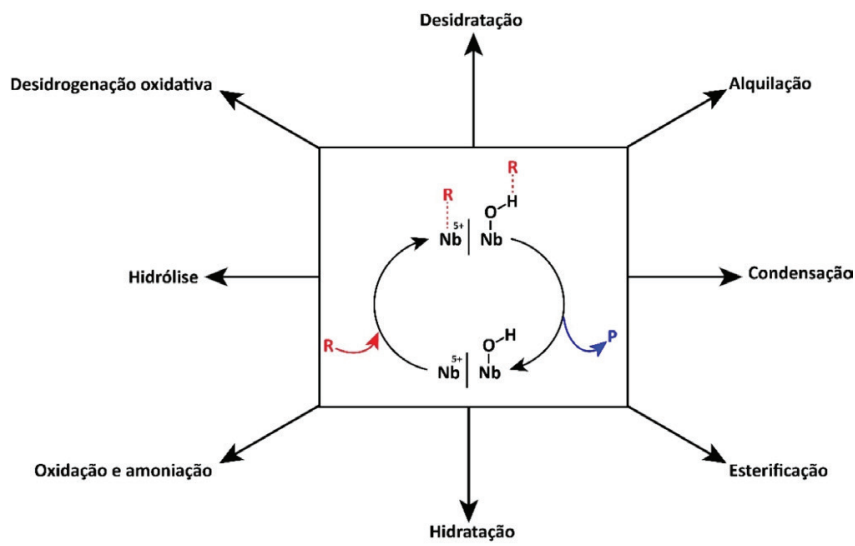

Figura 5. Exemplos de reações catalíticas utilizando compostos de nióbio ${ }^{45}$

Figura 5 mostra algumas das classes de reações em que os compostos contendo $\mathrm{Nb}$ são comumente utilizados. ${ }^{45}$

Recentemente, Lima e colaboradores ${ }^{46}$ mostraram que a modificação de $\delta$-FeOOH com oxidróxidos de nióbio resulta em catalisadores eficientes para a reação de oxidação de anilina em produtos de valor agregado como azoxibenzeno. Modificando o catalisador de $\delta$-FeOOH com $10 \%(\mathrm{~m} / \mathrm{m})$ de $\mathrm{Nb}$ leva a $100 \%$ de conversão de anilina com $80,2 \%$ de seletividade para azoxibenzene usando 1-propanol como solvente e $\mathrm{H}_{2} \mathrm{O}_{2}$ como oxidante a $25^{\circ} \mathrm{C}$. Oxidróxido de nióbio tem sido usado também para facilitar a absorção de luz visível por nanopartículas de $\mathrm{TiO}_{2} \cdot{ }^{47}$ Quando o oxidróxido de nióbio/ $\mathrm{TiO}_{2}$ é tratado com $\mathrm{H}_{2} \mathrm{O}_{2}$ são formados grupos peroxo-nióbio na superfície do $\mathrm{TiO}_{2}$ que leva a uma diminuição na energia entre as lacunas de bandas (band-gap) de 3,22 eV no $\mathrm{TiO}_{2}$ para 3,03 eV no $\mathrm{TiO}_{2}$ sensibilizado, possibilitando a ativação do fotocatalisador com luz visível. Grupos peroxo-nióbio têm sido também imobilizados na superfície de sílica mesoporosa dopada com nióbio previamente tratada com $\mathrm{H}_{2} \mathrm{O}_{2} \cdot{ }^{48}$ A substituição isomórfica de $\mathrm{Si}^{4+}$ por $\mathrm{Nb}^{5+}$ na estrutura da sílica produziu sítios ácidos que em conjunto com os grupos peroxo-nióbio na superfície da sílica produziu sítios altamente reativos para reações de oxidação. Diferentes estruturas de carbono como óxidos de grafeno, nanotubos de carbono e carvão ativado têm sido usados como suportes para imobilizar grupos peroxo-nióbio cataliticamente ativos para reações de oxidação. ${ }^{49}$ A presença de nióbio na superfície do óxido de grafite resultou no catalisador mais ativo para reações de oxidação de dibenzotiofeno em uma mistura bifásica de hexano/ acetonitrila. Catalisadores à base de $\mathrm{Nb}_{12} \mathrm{O}_{29}$ foram usados como um suporte reativo para deposição de $\mathrm{Fe}_{2} \mathrm{O}_{3}$ que funcionou como um catalisador do tipo-Fenton em presença de $\mathrm{H}_{2} \mathrm{O}_{2}$ para reação de oxidação de azul de metileno em meio aquoso. ${ }^{50}$ Óxidos de ferro (hematita e maghemita) dopados com nióbio têm apresentando alta atividade para degradar compostos orgânicos em meio aquoso em presença de $\mathrm{H}_{2} \mathrm{O}_{2}$. É interessante notar que esses catalisadores foram ativos por vários ciclos de oxidação consecutivos e após desativação os sítios catalíticos foram eficientemente regenerados após tratamento com $\mathrm{H}_{2} \mathrm{O}_{2}{ }^{51}$ A dopagem de goethita com nióbio tem causado um significativo aumento na área específica dos catalisadores o que resultou em excelente atividade catalítica para degradação de moléculas orgânicas em meio aquoso. Dados teóricos e experimentais sugeriram que o mecanismo de degradação é baseado nas vacâncias de oxigênio que surgem devido a substituição isomórfica de $\mathrm{Fe}$ por $\mathrm{Nb}$ na estrutura da goethita e em um mecanismo do tipo-Fenton envolvendo a geração de radicais a partir de reações química de $\mathrm{H}_{2} \mathrm{O}_{2}$ na superfície do oxidróxido de ferro. ${ }^{52,53}$ Compósitos de $\mathrm{Nb}_{2} \mathrm{O}_{5}$ com óxidos de ferro, e.g. goethita e maghemita, oxidam moléculas orgânicas através da formação de radicais $\mathrm{com}^{\bullet} \mathrm{OH}$ e ${ }^{\bullet} \mathrm{OOH}$ formados a partir da reação de $\mathrm{H}_{2} \mathrm{O}_{2}$ na superfície dos catalisadores. ${ }^{54}$

Catalisadores à base de nióbio têm sido usados também em reações de esterificação. Diferentes teores de nióbia foram impregnados em óxidos de grafeno para catalisar a reação de esterificação de ácido oleico com metanol. O rendimento máximo de $96,4 \%$ foi obtido para oleato de metila a $150{ }^{\circ} \mathrm{C}, 5 \%(\mathrm{~m} / \mathrm{m})$ de nióbia, razão molar de ácido oleico:metanol de 1:9 em 4h de reação. ${ }^{55}$ Ácido tungstofosfórico suportado em nióbia dopada com $1 \%(\mathrm{~m} / \mathrm{m})$ de césio produziu $90 \%$ de biodiesel a partir da esterificação de ácido oleico com metanol (razão molar 1:15) a $65^{\circ} \mathrm{C}$ em $8 \mathrm{~h}$ de reação. ${ }^{56} \mathrm{H}_{3} \mathrm{PMo}_{12} \mathrm{O}_{40}$ suportado em nióbia levou a produção de cerca de $99,65 \%$ de biodiesel a partir de simultânea esterificação e transesterificação de óleo de macaúba com alto teor de ácidos graxos livres e etanol (razão molar de 1:90) a $210{ }^{\circ} \mathrm{C}^{57} \mathrm{Nb}_{2} \mathrm{O}_{5}$ suportado em SBA-15 utilizado para catalisar a esterificação de ácido propanoico com metanol. Os autores encontraram que a atividade catalítica foi diretamente proporcional à razão ácido Brönsted-Lewis que pode ser controlada pelo teor de $\mathrm{Nb}$ na matriz de SBA-15. ${ }^{58}$

\section{CONCLUSÕES}

O nióbio, nos últimos anos, vem despertando interesse por parte de pesquisadores e do governo em virtude das propriedades interessantes, quando usado em ligas metálicas, como elevada resistência mecânica e maleabilidade. O nióbio também é utilizado na fabricação de vidros especiais, tais como lentes, películas de revestimento e capacitores cerâmicos. Quando usados como materiais anódicos em baterias de íons-lítio, esse metal (na forma de óxidos) proporciona alta capacidade volumétrica além de ser aplicado como supercapacitores híbridos. Na aplicação em catálise, área importante para a indústria química e petrolífera nacional, catalisadores a base de nióbio geralmente apresentam boa estabilidade química, acidez e versatilidade, ocupando um importante papel em reações catalíticas oxidativa. Ainda há muito do que se descobrir sobre esse estratégico elemento. Sendo o Brasil a sua maior reserva mundial em operação, uma gama de oportunidades surge, com possibilidade de geração de emprego e renda. Esse breve trabalho de revisão procurou atentar aos estudos que o nióbio vem se destacando, sob olhar tecnológico e de desenvolvimento do nosso país. Eventuais investimentos em infraestrutura como malhas ferroviárias, pontes, portos e a manufatura de carros híbridos, elétricos, compostos de nióbio podem ser estratégicos para geração de riqueza.

\section{AGRADECIMENTOS}

Fapemig, CNPq, Capes e CBMM. 


\section{REFERENCIAS}

1. Tarselli, M.; Nat. Chem. 2015, 7, 180.

2. Griffith, W.P.; Morris, P. J. T.; Notes Rec. R. Soc. 2003, 57, 299.

3. Wisniak, J.; Educ. Quim. 2015, 26, 346.

4. Canham, G. R.; Zheng, Z.; Found Chem. 2008, 10, 13.

5. Brasil. Ministério de Minas e Energia. Departamento Nacional de Produção Mineral - DNPM. Nióbio. Brasília, 2009; pp. 129-147.

6. Seer, H. J.; Moraes, J. C.; Nióbio - Recursos Minerais de Minas Gerais, UFMG: Belo Horizonte, 2018.

7. Brasil. Ministério de Minas e Energia. Departamento Nacional de Produção Mineral - DNPM. Sumário Mineral. Brasília; 2017; disponível em http://www.anm.gov.br/dnpm/publicacoes/serieestatisticas-e-economia-mineral/ sumário-mineralbrasileiro-2017/nióbio_sm_2017, acessado em outubro 2019.

8. https://commons.wikimedia.org/wiki/File:Pyrochlore-114105.jpg, acessado em outubro 2019.

9. Companhia Brasileira de Metalurgia e Mineração. Linha completa de produtos de nióbio de alta qualidade, disponível em https://www.cbmm. com/pt/Partner-with-CBMM/Products, acessado em outubro 2019.

10. Brasil. Ministério de Minas e Energia. Departamento Nacional de Produção Mineral - DNPM. Sumário Mineral, disponível em http:// www.anm.gov.br/dnpm/publicacoes/serie-estatisticas-e-economiamineral/sumário-mineral/sumario-mineral-brasileiro-2017, acessado em outubro 2019

11. Alves, A. R.; Coutinho, A. R.; Mater Res. 2015, 18, 106.

12. Brasil. Instituto Brasileiro de Mineração - IBRAM. Relatório Anual de Atividades Julho de 2017 a Junho de 2018. Brasília, 2018, disponível em http://portaldamineracao.com.br/ibram/wpcontent/uploads/2018/07/ Diagramação,_acessado em outubro 2019.

13. Brasil. Ministério de Minas e Energia. Secretaria de Geologia, Mineração e Transformação Mineral - SGM. Relatório Técnico : Perfil da Mineração do Nióbio, 2010, disponível em http://www.mme.gov. br/documents/1138775/1256650P11_RT20_Perfil_da_Mineraxo_do_ Nixbio.pdf/48860760-63f2-489e-b4b9-e16236, acessado em outubro 2019.

14. Charifoulline, Z.; IEEE Trans. Appl. Supercond. 2006, 16, 1188.

15. Special Materials: INCONEL® alloy 718, 2007, disponíevel em http:// www. specialmetals.com/assets/smc/documents/inconel_alloy_718.pdf, acessado em outubro 2019.

16. Neel, E. A.; Pickup, D. M.; Valappil, S. P.; Newport, R. J.; Knowles, J. C.; J. Mater. Chem. 2009, 19, 609.

17. Ahmed, I.; Collins, C. A.; Lewis, M. P.; Olsen, I.; Knowles, J. C.; Biomaterials 2004; 16, 3223.

18. Höland, W.; Beall, G. H.; Glass-Ceramic Technology, $2^{\text {nd }}$ ed., Wiley: New York, 2012.

19. Knowles, J. C.; J. Mater. Chem. 2003, 13, 2395.

20. Sene, F. F.; Martinelli, J. R.; Gomes, L.; J. Non-Cryst. Solids 2004, 348 , 30.

21. Tamai, M.; Isama, K.; Nakaoka, R.; Tsuchiya, T.; J. Artif. Organs. 2007; $10,22$.

22. Lopes, J. H.; Magalhães, A.; Mazali, I. O.; Bertran, C. A.; J. Am. Ceram. Soc. 2014, 12, 3843.

23. Sene, F. F.; Martinelli, J. R.; Gomes, L.; J. Non-Cryst. Solids 2004, 348, 30.
24. Mazali, I. O.; Barbosa, L. C.; Alves, O. L.; J. Mater. Sci. 2004, 39, 1987. 25. Justino, L. C.; Pastena, B.; Nardi, R.; Mater. Res. 2015, 18. 13.

26. Stunda, Z. A.; Vecstaudza, J.; Krieke, G.; Berzina, C. L.; Mater. Sci. Appl. Chem. 2017, $34,21$.

27. Kaur, G.; Pandey, O. P.; Singh, K.; Homa, D.; Scott, B.; Pickrell, G.; J. Biomed. Mater. Res., Part A 2014, 102, 254.

28. Tadjoedin, E. S.; Lange, G. L.; Lyaruu, D. M.; Kuiper, L.; Burger, E. H.; Clinical Oral Implants Research 2002, 13, 428.

29. Tan, F.; Zhang, Q.; Zhao, H.; Wei, F.; Du, J.; J. Electron. Mater. 2018 , 47, 2940.

30. Prasad, V.; Pavić, L.; Mogus, M. A.; J. Alloys Compd. 2019, 773, 654.

31. Sarmah, S. B.; Kalita, P.; Garg, A.; J. Electrochem. Energy Convers. Storage. 2019, 16, 1-12.

32. Yoo, Y., Kang, Y. C.; J. Alloys Compd. 2018, 738, 540-548.

33. Kim, K.; Hwang, J.; Seo, H.; Kim, H. S.; Kim, J. H.; J. Mater. Sci. 2019, 54, 2493.

34. Lin, J.; Yuan, Y.; Su, Q.; Electrochim. Acta. 2018, 292, 63.

35. Li, Y.; Wang, H.; Wang, L.; Small J. 2019, 18, 1.

36. Chen, J.; Wang, H.; Zhang, X.; Mater. Lett. 2018, 227, 112.

37. Li, Z.; Luo, C.; Wang, C.; J. Solid State Electrochem. 2018, 22, 2811.

38. Nowak, I.; Ziolek, M.; Chem Rev. 1999, 12, 3603.

39. Ziolek, M.; Sobczak, I.; Catal. Today 2017, 285, 211.

40. Pérez, M. O. G.; Catal. Today, no prelo.

41. Oliveira, L. C. A.; Portilho, M. F.; Silva, A. C.; Tarroco, H. A.; Souza, P. P.; Appl. Catal., B 2012, 117-118, 29.

42. Silva, A. C.; Cepera, V. M.; Pereira, M. C.; Lima, D. Q.; Oliveira, L. C. A.; Appl. Catal., B 2011, 107, 237.

43. SciVerse Scopus, disponível em https://www.scopus.com, acessado em outubro 2019.

44. Tanabe, K.; CHEMTECH 1991, 21, 628.

45. Ushikubo, T.; Iizuka, T.; Hattori, H.; Tanabe, K.; Catal. Today 1993, 16, 291.

46. Lima, A.L.; Batalha, D. C.; Fajardo, H. V.; Catal. Today 2018, $21,1$.

47. Oliveira, L. C. A.; Silva, A. C.; Pereira, M. C.; RSC Adv. 2015, 5, 44567.

48. Coelho, J.V.; Guedes, M.; Mayrink, G.; New J. Chem. 2015, 39, 5316.

49. Bozzi, A. S.; Lavall, R. L.; Souza, T. E.; Dalton Trans. 2015, 44, 19956.

50. Rezende, C. C.; Neto, J. L.; Silva, A. C.; Catal. Commun. 2012, 26, 209.

51. Silva, A. C.; Cepera, R. M.; Pereira, M. C.; Appl. Catal., B 2011, 107, 237.

52. Oliveira, L. C.; Ramalho, T. C.; Souza, E. F.; Appl. Catal., B 2008, 83, 169.

53. Oliveira, L. C. A.; Gonçalves, M.; Oliveira, D. Q.; Quim. Nova 2007, $30,925$.

54. Oliveira, L. C. A.; Gonçalves, M.; Guerreiro, M. C.; Appl. Catal., A 2007, 316, 117

55. Kanimozhi, S.; Pandurangan, A.; Hemalatha, P.; Indian J. Chem., Sect. A: Inorg., Phys., Theor. Anal. 2017, 56, 379.

56. Surasit, C.; Yoosuk, B.; Pohmakotr, M.; J. Am. Oil Chem. Soc. 2017, 94 , 465.

57. Conceição, L. R. V.; Carneiro, L. M.; Giordani, D. S.; Renewable Energy 2017, 113, 119 .

58. Silva, A.; Wilson, K.; Lee, A. F.; Appl. Catal., B 2017, 205, 498. 